Revista lus et Praxis, Año 22, № 2, 2016, pp. 153 - 188

ISSN 0717 - 2877

Universidad de Talca - Facultad de Ciencias Jurídicas y Sociales

La interpretación conforme con la Constitución: una aproximación conceptual José Ángel Fernández Cruz

Trabajo recibido el 24 de julio y aprobado el 30 de noviembre de 2015

\title{
La interpretación conforme con la Constitución: una aproximación conceptual ${ }^{*}$
}

THE INTERPRETATION ACCORDING TO THE CONSTITUTION:

A CONCEPTUAL APPROACH

José Ángel Fernández Cruz

\begin{abstract}
Resumen
La interpretación conforme con la Constitución constituye un ejemplo más del fenómeno de constitucionalización del Derecho. Estamos ante una forma de creación o cambio normativo sin modificación de texto. Su autonomía conceptual reside en establecer "condiciones interpretativas de constitucionalidad". Constituye tanto una técnica de control de constitucionalidad como una forma de interpretación. A partir de una concepción crítica del Derecho, la interpretación de la ley conforme con la Constitución debe cumplir una función de garantía de los derechos fundamentales y de transformación social. No existe una diferencia estructural entre la interpretación conforme con la Constitución realizada por los tribunales constitucionales y la interpretación orientada hacia la Constitución realizada por los tribunales ordinarios. Los tribunales constitucionales deben sólo centrarse en declarar aquellas interpretaciones que resultan claramente contrarias a la Constitución, ya que la determinación de la mejor interpretación posible de acuerdo a la Constitución corresponde a los tribunales ordinarios (superiores).
\end{abstract}

ABSTRACT

Interpretation according to Constitution (constitutional avoidance canon) is an example of the constitutionalization of law phenomenon (in Civil law). It's a creation of legal norms without legal provision or written law. Its conceptual autonomy lies in establishing "constitutional conditions of interpretation." On the basis of a critical or alternative legal approach interpretation according to Constitution should protect fundamental rights and participate in social transformation processes as an instrument of social change. There is not a structural difference between interpretation according to Constitution made by Constitutional Courts and the so called interpretation guide to Constitution made by other Courts of Justice. This article claims that Constitutional Court should

* Estudio comprometido en el Proyecto Fondecyt Regular No 1130076. El autor agradece a los profesores de la Facultad de Ciencias Jurídicas y Sociales de la Universidad Austral por las sugerencias y críticas (constructivas) que realizaron a este estudio con ocasión de su discusión en el Seminario Austral de Derecho y, en especial, al profesor Álvaro Núñez Vaquero. Este agradecimiento se extiende a los evaluadores de la revista lus et Praxis.

** Profesor de Derecho Penal de la Facultad de Ciencias Jurídicas y Sociales de la Universidad Austral de Chile. Correo electrónico: josefernandez@uach.cl. 
focus in declaring what interpretations are clearly unconstitutional, otherwise establishing the best possible interpretation falls within the jurisdiction given to Courts of Justice.

Palabras Clave

Interpretación conforme con la Constitución, Teoría de la interpretación, Tribunal

Constitucional

KEYWORDS

Constitutional avoidance canon, Interpretation theory, Constitutional Court

\section{Introducción}

Las constituciones modernas y las sociedades cada vez más pluralistas demandan unas técnicas y métodos de interpretación que den respuestas a los conflictos que se producen en su seno, en las que el formalismo, la neutralidad axiológica y la racionalidad intrínseca del legislador cada vez se ven más comprometidas. Esta demanda no sólo procede de la ciudadanía, sino también del creciente protagonismo de las jurisdicciones constitucionales, y también ordinarias, en la tutela de los derechos fundamentales. La interpretación constitucional se convierte, por tanto, en una de las cuestiones clave del Derecho contemporáneo ${ }^{1}$. Una de las manifestaciones de este creciente protagonismo de la interpretación constitucional es la denominada interpretación conforme con la Constitución (en lo sucesivo ICC).

Como una primera aproximación podemos definirla como una interpretación de una norma infraconstitucional de acuerdo con la Constitución, que tiene como finalidad evitar una sentencia estimativa de inconstitucionalidad. A la vez, esta interpretación se compone de un aspecto positivo y otro negativo. Este último consiste en la expulsión de la comunidad jurídica de una interpretación o contenido normativo; en cambio, el primero consiste en la interpretación o comprensión de la norma infraconstitucional de acuerdo con la Constitución. La faceta negativa constituye, para la mayor parte de la doctrina, su característica o efecto distintivo; en cambio, respecto de la faceta positiva, se discute su pertinencia desde consideraciones institucionales, en especial respecto; a la función unificadora de la jurisprudencia de los tribunales superiores ${ }^{2}$.

La jurisprudencia constitucional y la doctrina nacional han reconocido la necesidad u obligatoriedad de la ICC IC $^{3}$ Así, la mayor parte de la doctrina ha fundamentado su función hermenéutica en el valor supremo y normativo de la

\footnotetext{
1 Por todos, Landa (2005), p. 80.

2 Véase infra 4.1.

3 Véase la doctrina citada en: SILvA (2014), pp. 439 y ss.
} 
Constitución ${ }^{4}$. En el mismo sentido, el Tribunal Constitucional (en lo sucesivo TC) ha venido utilizando este criterio hermenéutico como un principio general en el control de constitucionalidad de las normas ${ }^{5}$, y -desde la reforma de la Constitución de 2005- ha ampliado esta forma de control a las cuestiones de inaplicabilidad y constitucionalidad ${ }^{6}$. Incluso, el TC ha considerado la ICC como una obligación 7 .

El presente estudio pretende contribuir a la discusión nacional con una aproximación conceptual a la ICC desde tres perspectivas. En la primera de ellas, se mencionarán las principales características de la ICC a partir de la teoría de la interpretación; en la segunda, se mencionarán las implicancias de los principales modelos o paradigmas teóricos sobre la interpretación constitucional, y en la tercera se abordará su supuesta autonomía conceptual, especialmente respecto de la denominada interpretación orientada a la Constitución. Este estudio ha tomado como referencia el Derecho Penal, debido, por una parte, a la formación académica de su autor y, por otra, porque ha sido en este ámbito, como evidencia Núñez Poblete, donde más se ha prodigado la ICC en nuestra jurisprudencia constitucional ${ }^{8}$.

Si partimos de la existencia de una tensión institucional entre los tribunales constitucionales y el poder legislativo o los tribunales ordinarios, en especial cuando aquéllos realizan una ICC positiva ${ }^{9}$ o cuando estos últimos expulsan contenidos normativos de la comunidad jurídica, entonces resulta necesario, como hipótesis de trabajo, establecer unos criterios de interpretación de segundo orden que nos permitan determinar cuándo resulta razonable acudir a una ICC.

\section{Aproximación conceptual la ICC a partir de la teoría de la interpretación}

En la actualidad, nadie pone en duda la necesidad e importancia de la interpretación en el Derecho; sin embargo, surgen múltiples discrepancias a la hora de caracterizar en qué consiste y cómo debe llevarse a cabo. No pretendemos aquí desarrollar y justificar una teoría de la interpretación jurídica, sino sólo señalar aquellas características o reconstrucciones desarrolladas en

\footnotetext{
4 Véanse, entre otros, Soto (1996), pp. 68-69; Nogueira (2009), p. 168; Aldunate (2009), p. 446; Verdugo et al. (1994), pp. 132 y 132. Una visión crítica a esta doctrina: SiLva (2012), pp. 573-616.

5 Véase la jurisprudencia del Tribunal Constitucional citada en PIÑA (2012), pp. 121-126.

6 Véase Zapata (2006), pp. 178 y ss., STC, roles 806, de 11 de diciembre de 2007 y 791, de 15 de enero de 2008.

7 Véase, la STC, rol 1584, de 31 de diciembre de 2009 y la jurisprudencia citada.

8 NúÑ̃z (2008), pp. 35 y ss.

9 Véase infra, Aproximación conceptual.
} 
el seno de la teoría del Derecho ${ }^{10}$ que puedan ayudarnos a comprender en qué consiste la ICC ${ }^{11}$.

Podemos comenzar, de acuerdo con Wróblewski, definiendo la ICC como un tipo de interpretación en sensu estricto, es decir, como una comprensión de entidades lingüísticas sobre las cuales existen dudas acerca de su significado ${ }^{12}$. Esta duda interpretativa, de acuerdo con la formulación de la ICC en el derecho estadounidense, puede consistir en la concurrencia de dos o más interpretaciones del texto infraconstitucional, donde al menos una de ellas resulta inconstitucional y otra válida (classical avoidance); o cuando la interpretación más correcta, desde el punto de vista de los cánones clásicos, plantea serias dudas sobre su constitucionalidad (modern avoidance) $)^{13}$. En este caso, el TC interpretará la norma de tal manera que se evite la declaración de inconstitucionalidad, aunque se aparte claramente de esta interpretación ${ }^{14}$.

Quizá una de las características más relevante de la ICC desde la teoría de la interpretación radica en el hecho de que evidencia con total nitidez la problemática sobre el enunciado normativo y la norma (entre el significante y el significado), ya que el TC, sin modificar el texto de la ley, no sólo puede modificar su contenido, sino también crear o descubrir una norma de rango constitucional ${ }^{15}$. Ahora bien, la ICC en su dimensión negativa no establece de

10 En especial, tomaré como referencia a los autores que entienden el Derecho como una práctica interpretativa (Dworkin y Atienza, entre otros).

11 Las siguientes líneas toman como referencia a LIFANTE (2015), pp. 1349-1387.

12 WróbleWSKI (1985), pp. 21 y ss. El autor citado diferencia entre interpretación sensu largissimo, que es aquella que se realiza sobre cualquier entidad portadora de sentido, y la interpretación sensu largo, que se predica sobre entidades lingüísticas con independencia de si existe o no una duda sobre su significado.

13 Debe destacarse que el ámbito de aplicación de este canon se amplía, ya que no sólo comprende los casos en que una interpretación es (claramente) contraria a la Constitución, sino también cuando ésta presenta serias dudas sobre su constitucionalidad.

14 En la doctrina y jurisprudencia estadounidense, la versión moderna de este canon se centra en derrotar la voluntad del legislador, a menos que ésta se encuentre claramente expresada en el texto de la ley. Por todos, Young (2000), pp. 1575-1576. No obstante, el autor citado critica esta compresión de este canon y, por el contrario, entiende que, cuando, los jueces acuden a éste, lo que realmente están aplicando son valores constitucionales (implícitos) más que valores o intenciones del legislador. Young (2000), pp. 587 y ss.

15 La posibilidad de que una ICC pueda modificar el contenido normativo de la Constitución nos adentra en la problemática de la denominada mutación constitucional, entendida ésta, en una primera aproximación, como la modificación del contenido normativo de la Constitución sin haber un cambio formal al texto escrito. Desde su formulación por Jellinek, la teoría constitucional se ha ocupado sobre su legitimidad, fundamento y límites o condiciones de aplicabilidad. El problema que se plantea en último término es la admisión de la mutación constitucional como un mecanismo legítimo de modificación de normas constitucionales. Ahora bien, si dejamos fuera los casos de "contradicción notoria", 
manera directa un contenido normativo a partir del texto infraconstitucional, sino de manera indirecta, es decir, al expulsar una determinada comprensión del texto, otorga preponderancia o validez a otros contenidos normativos. En cambio, la ICC en su dimensión positiva sí atribuye de manera directa un determinado significado a la disposición infraconstitucional.

Un ejemplo paradigmático de cambio normativo sustancial de una disposición normativa a través de una ICC lo encontramos en la STC español 12/2004, de 24 de febrero, donde sometió a su jurisdicción el primer inciso del artículo 563 CP español ("La tenencia de armas prohibidas") por una posible vulneración del mandato de certeza. El TC español terminó dictando una sentencia interpretativa, conforme a la cual las armas cuya tenencia se prohíbe penalmente son exclusivamente aquellas que cumplan con unos determinados requisitos. En primer lugar, deben constituir materialmente armas (pues no todos los objetos son armas en sentido estricto, de acuerdo con la normativa reglamentaria española). En segundo lugar, su tenencia debe ser prohibida por una norma extrapenal con rango de ley o por el reglamento al que la ley remita. En tercer lugar, deben poseer una especial potencialidad lesiva. Y, por último, la tenencia, para considerarse delictiva, debe producirse en unas circunstancias que la conviertan en el caso concreto en especialmente peligrosa ${ }^{16}$.

Relacionado con la anterior afirmación, la ICC constituye otro claro signo del proceso de constitucionalización del Derecho. Así, a partir de una determinada compresión de la Constitución, se realiza una interpretación correctora de la norma infraconstitucional que puede ser extensiva, si amplía los supuestos de hechos subsumibles, o restrictiva, si, por el contrario, los reduce ${ }^{17}$. En este

cualquiera otra variante de la mutación constitucional es reconducible a la interpretación. A tenor de lo anteriormente expuesto, cuando el Tribunal Constitucional realiza previamente una interpretación de una norma constitucional que sirva de acomodo de una interpretación de una norma infraconstitucional $y$, de esta manera, evita una sentencia declarativa de inconstitucionalidad, se encuentra sometido a los límites de la interpretación, cualesquiera que sean éstos (el sentido literal posible y/o voluntad o sentido de la norma y, en el ámbito penal, los establecidos del mandato de lex stricta). En conclusión, la denominada mutación constitucional se equipara a la interpretación constitucional o estamos ante un fenómeno patológico de la jurisprudencia constitucional, que puede tener una justificación política o sociológica en casos excepcionales, pero que, en ningún caso, puede tener cabida en la teoría constitucional, siempre y cuando entendamos a los tribunales constitucionales como órganos con una función esencialmente jurisdiccional. Véase un reciente estudio sobre esta problemática en ROLLNERT (2014), pp. 125-155.

16 STC español 12/2004, de 24 de febrero (fundamento jurídico 8).

17 Por todos, GuAstini (1999), p. 359. El reconocimiento de la ICC en el derecho comparado abarca tanto a los sistemas jurídicos de tradición romanista como a los anglosajones (common law). El TC alemán aplicó o reconoció por primera vez el recurso de la ICC en los siguientes términos: "Una ley no debe ser declarada nula si fuera posible interpretarla de forma compatible con la Constitución, pues se debe presuponer no solamente que una ley sea compatible con la Constitución, sino también que 
sentido, cuando el TC realiza una ICC, en especial en su faceta positiva, puede comprender algunas de estas dos formas: los pronunciamientos meramente declarativos, en los que el TC sólo reproduce los contenidos normativos, que ya se encontraban presentes en la praxis jurisprudencial ordinaria, y los pronunciamientos interpretativos auténticos, en los que el TC introduce ex novo elementos que condicionan la comprensión del precepto legal más allá de la interpretación asentada en otras instancias jurisdiccionales ${ }^{18}$.

También podemos caracterizar la ICC, por un lado, como proceso, y, por otro, como resultado interpretativo. Como proceso, siguiendo a Gianformaggio, la ICC constituye una forma de interpretación dianoética, es decir, una compresión de las entidades lingüísticas en la que se requiere un pensamiento discursivo, una argumentación; en contraposición con la interpretación noética, donde sólo se requiere un pensamiento intuitivo, una captación intelectual inmediata ${ }^{19}$. La ICC entendida como resultado, de acuerdo con la anterior clasificación, es una proposición del tipo: "S" (el signo S) debe entenderse como " $\mathrm{S}^{\prime \prime}$ (tiene el significado

esa presunción expresa el principio según el cual, en caso de duda, debe hacerse una interpretación conforme con la Constitución". BVerGE, 266 (282). La Corte Federal Suiza ha afirmado en reiteradas ocasiones que "en el control abstracto de constitucionalidad, solamente debe declarar la nulidad de una disposición del derecho cantonal, si no se presta a ninguna ICC". BGE 109, 207. Sentencias citadas y traducidas por DA SILVA (2005), p. 5. La primera oportunidad en que la Corte Suprema estadounidense expresó el principio de que no puede declararse la inconstitucionalidad de una ley si no existe una evidencia manifiesta de que ésta es incompatible con la Constitución, data de 1796 en el voto de minoría del juez Samule Chase en el caso Hylton vs. United States. Con posterioridad la Corte Suprema ha reconocido en numerosas ocasiones esta forma de control de constitucionalidad. Así, una de las formas más acabadas de este reconocimiento la encontramos en el caso N.L.R.B. vs Jones \& Laughlin Corporation, resuelto en 1937. Esta sentencia estableció que, entre dos interpretaciones de una ley, donde una podría ser inconstitucional y otra no, constituye un deber de la Corte Suprema adoptar aquella que salve la ley (avoidance canon). Desde entonces, la necesidad de no declarar la inconstitucionalidad de una ley que pueda ser interpretada conforme con la Constitución constituye una de las "great maxims of judicial self-restrains" en el ejercicio de la judicial review of legislation, precedente vinculante para todos los jueces de la federación. No obstante, si bien existe acuerdo histórico en reconocer que la técnica de ICC aparece por primera vez en el modelo norteamericano, su desarrollo en Europa pareciese no tener como precedente la jurisprudencia de la Corte Suprema estadounidense, sino que se produjo de manera instantánea y con completa independencia de su antecedente norteamericano. Así, podemos encontrar su primer precedente en el Tribunal del Reich de la República de Weimar. No obstante, la edad de oro de las decisiones interpretativas se produce a partir de la II Guerra Mundial; primero en Austria y en el Tribunal Constitucional de Baviera y después en el propio Tribunal Constitucional Federal Alemán. Véase en extenso doctrina y jurisprudencia en LÓPEZ (2004), pp. 90 y ss.

18 En el mismo sentido, LóPEZ (2004), p. 512.

19 Gianformaggio (1987), pp. 90 y ss. Como manifiesta Lifante, toda situación comunicativa necesita de una interpretación noética, pero no de una dianoética. Lifante (2015), p. 1351; Soto (1996), pp. 68-69; Nogueira (2009), p. 168; Aldunate (2009), p. 446; Verdugo et al. (1994), pp. 132 y ss. Una visión crítica a esta doctrina: SILvA (2012), pp. 573-616, nota 4. 
"S"). La diferencia entre interpretación como proceso y como resultado puede verse con más claridad con el siguiente esquema, propuesto por Atienza:

1. Enunciado a interpretar: el texto normativo.

2. Enunciado interpretativo: el enunciado por el cual resolvemos el problema interpretativo.

3. Enunciado interpretado: la sustitución en la disposición objeto de interpretación de la expresión que plantea dudas por la expresión en la que se ha resuelto la ambigüedad sintáctica.

Así, tomando como ejemplo la STC de 27 de febrero, rol 739-07, que resolvió un requerimiento de inaplicabilidad respecto del delito de asociación ilícita previsto en el artículo 292 del CP, el enunciado a interpretar residió en la expresión "por el solo hecho de organizarse". A partir de una interpretación literal, este término significa que una organización de personas estructurada jerárquicamente y con permanencia en el tiempo se considerará como ilícita sin necesidad de que se haya cometido previamente ningún delito. La duda que se planteó es si, de acuerdo con nuestra Constitución, la asociación requería algún tipo de conducta previa peligrosa por parte de alguno de sus miembros. EI TC entendió que, a pesar de estar este delito estructurado como un delito de peligro abstracto, este tipo de delitos vulnerarían el principio de lesividad y la prohibición constitucional de presumir de derecho la responsabilidad penal. Así, para evitar la declaración de inconstitucionalidad, el TC estableció el siguiente enunciado interpretativo: "por el solo hecho de organizarse" ha de entenderse como la concurrencia de "efectivas acciones antijurídicas y no únicamente de una voluntad delictual por la mera existencia de una organización". Por último, el enunciado interpretado sería, en palabras del TC, el siguiente: "toda asociación formada con el objeto de cometer de atentar contra el orden social, contra las buenas costumbres, contra las personas o las propiedades, importa delito cuando hayan concurrido en su seno efectivas acciones antijurídicas". Al menos en este ejemplo, el enunciado interpretativo resulta más general que el enunciado interpretado, ya que no sólo resuelve el problema interpretativo del artículo 292 del CP, sino que afecta, en principio, a todos los delitos de peligro abstracto, en el sentido de que requieren un contenido antijurídico (mínimo) y no meramente formal.

En cuanto al objeto de la ICC, en principio pareciese que se refiere a la "ley", entendida en un sentido amplio, como equivalente a cualquier fuente del Derecho que tiene su origen en una autoridad política; no obstante, existen otras concepciones que amplían el objeto de la interpretación al propio Derecho en el que, junto con la aclaración del sentido de la ley, se incluye u otorga mayor importancia a la integración de las propias fuentes normativas. Su objeto estaría formado tanto por la suma de textos jurídicos como por la propia práctica jurídica. Así, junto a las teorías de orientación más o menos analítica, tenemos 
las concepciones críticas del Derecho (por ejemplo, el realismo jurídico norteamericano) o teorías de influencia hermenéutica, como por ejemplo la propuesta de Dworkin, que se decantan por esta comprensión de la interpretación. Nos encontramos con una actividad más compleja que la mera atribución de significado a un texto normativo: se incluye, además de la atribución de significado a un segmento del discurso legislativo, la resolución de antinomias, la integración de la ley, etcétera ${ }^{20}$. Si tenemos presente que la ICC constituye un mecanismo para salvar una ley que, interpretada analíticamente, resulta inconstitucional, entonces podemos afirmar que su objeto es el Derecho y no sólo la ley.

La ICC pareciese ser un tipo de interpretación en abstracto, es decir, entendida como una atribución de significados a texto jurídicos, en contraposición de la interpretación en concreto, dirigida a identificar los casos regulados por cada norma. Ahora bien, esto no significa que la interpretación en abstracto deba ignorar los hechos concretos, realizada a la luz de todas las circunstancias del caso, el momento histórico, las reformas legislativas habidas, etc. Guastini entiende que la interpretación en abstracto constituye -desde un punto de vista lógico- un proceso anterior a la interpretación en concreto, entendida como la subsunción de un caso concreto en el campo de aplicación de una norma previamente identificada en "abstracto". Ahora bien, desde un punto de vista empírico y sicológico ambos tipos de interpretaciones pueden y suelen realizarse de manera conjunta ${ }^{21}$. Por tanto, si consideramos la ICC como una interpretación en abstracto, ésta constituye el primer proceso y resultado interpretativo en el control de constitucionalidad de las leyes.

A partir de la clasificación entre interpretación de la ley y del Derecho, por una parte, e interpretación en abstracto y en concreto, por otra parte, Lifante establece el siguiente cuadro explicativo ${ }^{22}$ :

\begin{tabular}{|c|l|l|}
\hline & \multicolumn{1}{|c|}{ Interpretación de la ley [1] } & \multicolumn{1}{|c|}{ Interpretación del derecho [2] } \\
\hline $\begin{array}{c}\text { Interpretación } \\
\text { en abstracto [A] }\end{array}$ & $\begin{array}{l}\text { 1.A } \\
\text { (precisión del significado de disposi- } \\
\text { ciones jurídicas). }\end{array}$ & $\begin{array}{l}\text { 2.A } \\
\text { (reconstrucción, sistematización de } \\
\text { instituciones). }\end{array}$ \\
\hline $\begin{array}{c}\text { Interpretación } \\
\text { en concreto [B] }\end{array}$ & $\begin{array}{l}\text { 1.B } \\
\text { (calificación jurídica de un caso } \\
\text { concreto). }\end{array}$ & $\begin{array}{l}2 . \text { B } \\
\text { (solución a un problema jurídico). }\end{array}$ \\
\hline
\end{tabular}

20 Lifante (2015), p. 1357.

21 Guastini (1999), p. 204.

22 Lifante (2015), p. 1374. 
La distinción entre [1] y [2] hace referencia a dos sentidos de interpretación que conllevan un distinto alcance en cuanto a las actividades implicadas. El primero, el que encontramos implícito en el uso de la expresión "interpretación de la ley", sería un concepto más estricto de interpretación jurídica, según el cual interpretar supone aclarar el significado de una expresión contenida en una disposición jurídica. A su vez, dentro de este primer supuesto podría realizarse una clasificación atendiendo a si tal actividad se plantea en abstracto (sería el supuesto [1.A]), o bien es realizada a partir de un determinado problema concreto, es decir, si puede plantearse también como una cuestión de calificación (sería el supuesto [1.B]).

El supuesto [2] (la "interpretación del Derecho") se trata, como hemos visto, de un concepto bastante más amplio de actividad interpretativa que el supuesto anterior. Su objetivo radica en la unidad del Derecho a través de la reconstrucción o integración de los textos jurídicos. Si se trata de reconstruir el sistema jurídico a partir del planteamiento de un determinado caso -no necesariamente individual- al que debe darse solución, estamos ante una interpretación en "concreto" (sería el supuesto [2.B]). Pero esta actividad también puede darse en un contexto muy distinto. Piénsese, por ejemplo, en los casos en que la doctrina reconstruye una parcela del Derecho de manera unitaria o sistemática; dicha reconstrucción no se plantea a partir de un caso, sino de una determinada institución. En estos casos, la finalidad inmediata perseguida no sería práctica (no se busca la solución a un problema concreto), sino fundamentalmente cognoscitiva y se interpretaría -podríamos decir- "en abstracto". Esta actividad es la que se incardinaría precisamente en la casilla [2.A].

La ICC constituye un ejemplo de interpretación judicial que no tiene por objeto la interpretación orientada hacia los hechos (planteada a partir de un determinado problema particular al que debe darse solución), sino la interpretación en abstracto (al margen de situaciones concretas) u orientada hacia los textos. Así, continuando con la STC relativa al delito de asociación ilícita, la ICC puede consistir en una precisión del texto normativo comprendido en el artículo 292 del CP [1.A] o como reconstrucción de los delitos de peligro abstracto [2.A ${ }^{23}$.

La conceptualización de la interpretación según el sujeto que la lleva cabo también incide en la comprensión de la ICC. Esta clasificación es caracterizada en realidad atendiendo no a las peculiaridades que reviste la actividad interpretativa que llevan a cabo los distintos sujetos de la interpretación, sino a los distintos efectos que el sistema jurídico concede al resultado de cada una de

23 Nuestro TC ha llevado a cabo interpretaciones conformes con la Constitución en el contexto del requerimiento de inaplicabilidad y, por tanto, estamos ante un ejemplo más de que este tipo de procedimiento no sólo alberga controles concretos de constitucionalidad. 
esas interpretaciones. Una determinada interpretación realizada por un órgano judicial de cierta jerarquía puede resultar vinculante para los órganos inferiores, y así, por ejemplo, en ocasiones se habla de que el Tribunal Constitucional es el intérprete auténtico de la Constitución, queriendo remarcar con ello la vinculación de todos los destinatarios jurídicos a los resultados interpretativos a los que Ilega este tribunal. Ahora bien, en el caso de la ICC, el TC se convierte no sólo en el máximo intérprete de la Constitución, sino también en el máximo intérprete de las normas infraconstitucionales de acuerdo con la propia Constitución.

Otro aspecto relevante de la ICC es su relación con los denominados cánones interpretativos o, desde un punto de vista más general, como práctica argumentativa. Desde su caracterización por Savigny en el siglo XIX, constituyen los principales medios por los cuales se argumenta a favor de una determinada interpretación. Cuando se habla de ICC, no se está haciendo referencia a la interpretación constitucional, pues no es la propia Constitución, en principio, la que deber ser interpretada ${ }^{24}$, sino la interpretación de las normas infraconstitucionales ${ }^{25}$. Por tanto, la ICC podría entenderse que forma parte de los cánones clásicos de interpretación de las normas jurídicas (histórico-legislativo, sistemático, teleológico). Pero para otra parte de la doctrina no se trata de un criterio de interpretación de la ley, ya que la ICC previamente demanda una interpretación de la norma infraconstitucional de todos los sentidos razonablemente posibles mediante los cánones hermenéuticos aceptados por la teoría del Derecho ${ }^{26}$. Es considerada por esta doctrina como un criterio interpretativo inmanente o consustancial a la justicia constitucional ${ }^{27}$. Entendemos, por el contrario, que la ICC constituye, desde un punto de vista estructural, una interpretación sistemática: una determinación del sentido de la ley a través de las normas constitucionales, sin perjuicio de que el TC pueda acudir al resto de los cánones interpretativos para fundamentar su compresión de la norma infraconstitucional.

Relacionado con los cánones clásicos de la interpretación, la ICC en su faceta negativa responde a uno de los problemas fundamentales de la interpretación que puso ya de manifiesto Kelsen: la posibilidad de atribuir diferentes significados a los enunciados normativos y la ausencia de metacriterios jurídicos que establezcan qué criterio debe aplicarse en cada caso. En sentido estricto, lo que faltaría serían metacriterios últimos para establecer cuál es la

\footnotetext{
24 Como hemos manifestado, resulta posible que el TC, al llevar a cabo una ICC, se vea compelido a interpretar el propio texto constitucional. Incluso, con la finalidad de acomodar una determinada ICC, que el TC cambie el contenido normativo de la propia Constitución.

25 Da SiLva (2005), p. 10.

26 FERRERES (2007), p. 37.

27 Por todos, CarpIO (2008), p. 157.
} 
interpretación correcta. En efecto, a partir de Wróblewski, es frecuente distinguir entre criterios interpretativos de primer y segundo orden. Los primeros son reglas lingüísticas que establecen significado para los enunciados; los segundos serían reglas sobre el uso de los criterios de primer orden (reglas de preferencia y exclusión ${ }^{28}$. Pues bien, cuando el TC con la finalidad de evitar una sentencia de inconstitucionalidad excluye una determinada interpretación de una norma infraconstitucional de acuerdo con alguno de los cánones interpretativos a partir de una determinada comprensión de la Constitución, lo que está aplicando es una regla interpretativa de segundo orden ${ }^{29}$.

Dentro de las teorías de la interpretación, la ICC puede ser entendida tanto como una de tipo escéptica como una de tipo cognitivista. Para la primera, el hecho de que los tribunales constitucionales resultan muy permeables a consideraciones políticas, el carácter especialmente abierto de las normas constitucionales y su condición de último intérprete de la Constitución son argumentos para concluir que estamos ante un acto de mera voluntad y, por lo tanto, desde la teoría de la interpretación, lo único que cabe es una descripción de los argumentos esgrimidos por éstos. En último término, estamos ante un acto de creación del Derecho. Las teorías cognitivistas entienden, por el contrario, que resulta posible conocer la interpretación verdadera, al menos, la más correcta. Posiciones intermedias, como la propuesta por Hart, que diferencia entre la interpretación como actividad esencialmente cognitiva o noética (aplicada a los casos fáciles) y como actividad esencialmente volitiva o dianoética (referida a casos difíciles) ${ }^{30}$. Para autores como Dworkin, MacCormick, Alexy y Atienza, si la interpretación (en abstracto) implica atribuir a una disposición un significado, esto supone dar buenas razones para preferir dicho significado que, en último término, supone una pretensión de corrección. Por tanto, podríamos decir que existen criterios de corrección en la ICC, en especial, en su faceta positiva, a pesar de su alto contenido de discrecionalidad.

Finalmente, la ICC, en especial en su aspecto positivo ${ }^{31}$, puede ser entendida no como la manera de conocer o acceder al Derecho, sino como argumentación.

\footnotetext{
28 NúÑ̃z (2014), p. 418 y nota 8. Así, Núñez plantea, desde un punto de vista escéptico, que carecemos de criterios interpretativos de tercer grado para resolver los conflictos entre las reglas de segundo orden. Véase WRÓBLEWSKI (2001). Para un análisis crítico de estas tesis, véase BASCUÑán (2014).

29 Un ejemplo paradigmático son los casos en que el TC expulsa interpretaciones o contenidos normativos que han sido descubiertos o construidos a partir de concepciones histórico-legislativas u originalistas de la ley.

30 LiFANTE (2015), pp. 1377-1378.

31 Respecto a su aspecto negativo, es decir, la expulsión de un determinado contenido normativo, si bien resulta más problemática su comprensión como argumentación, ya que no construye el Derecho,
} 
Aquí, la interpretación es vista como una práctica social, como una construcción de los contenidos normativos que no son descubiertos, sino atribuidos por la propia interpretación. El Derecho es una práctica social que se compone tanto de un conjunto de reglas como de una serie de valores que dichas reglas pretenden desarrollar. Dworkin, el principal exponente de esta teoría, propone un modelo de interpretación articulado en tres etapas. La primera, denominada "preinterpretativa", identifica y califica el objeto interpretado dentro de un determinado género. La segunda, que sería la "propiamente interpretativa", trata de averiguar cuál es el sentido del problema jurídico a través de la identificación de los principios (valores y propósitos) que fundamentan el objeto interpretado. Como resulta frecuente que el mismo objeto interpretado sea deudor de varios principios, incluso alguno de ellos en conflicto, existen varias teorías que pugnan entre sí para construir el Derecho a partir de los materiales jurídicos existentes. La labor en esta etapa es, por tanto, identificar las distintas interpretaciones o teorías sobre el objeto interpretado. La tercera etapa es la que Dworkin denomina como "postinterpretativa". Ésta consiste en elegir una de las propuestas interpretativas de la etapa anterior. Aquí debe determinarse, de acuerdo a los valores que se consideran valiosos para un determinado género, qué teoría permite mostrar el objeto interpretado como el mejor caso posible al que se considera que pertenece. En esta etapa, Dworkin toma como referencia al juez (imparcial) que debe resolver un determinado conflicto interpretativo. Así, los textos normativos o fuentes del Derecho son Derecho, pero en un estado preinterpretativo, mientras que la realidad del Derecho se encontraría en los procesos interpretativo y postinterpretativo ${ }^{32}$.

Esta comprensión del proceso interpretativo tiene una especial relevancia en el caso de la ICC. En primer lugar, porque el TC, entendido como órgano jurisdiccional, debe decidir cuál es la que mejor se adecua a la Constitución entre las diferentes teorías o propuestas interpretativas sobre la norma infraconstitucional. En segundo lugar, porque gran parte de las normas constitucionales que van a servir de parámetro para interpretar la norma infraconstitucional son valores positivizados. Y, en tercer lugar, porque la ICC constituye un ejemplo paradigmático del Derecho como argumentación, en el que el contenido normativo no se determina a través de los textos normativos o de interpretaciones noéticas, sino a través de la interpretación dianoética. Estamos normalmente ante casos difíciles.

sino que lo destruye, entendemos que requiere un discurso jurídico que incide de manera indirecta a la atribución de significados jurídicos.

32 Lifante (2015), p. 1384. 
La interpretación como argumentación supone que el intérprete no sólo debe guiarse por razones de corrección y finalistas, sino que también debe atender a consideraciones pragmáticas (dialécticas y retóricas). Estas razones, que podemos también denominar discursivas, se manifiestan en el carácter contradictorio de los procesos constitucionales, en las deliberaciones del tribunal que se replican en la redacción del fallo y, en especial, en los denominados votos particulares (discrepantes o concordantes).

Ahora bien, la dialéctica constitucional no se encuentra sometida de manera completa a las reglas procedimentales de una "comunidad ideal de diálogo" de Habermas, ni de la "razón pública" de Rawls. En primer lugar, este tipo de argumentación no se encuentra abierta a toda la comunidad, sino sólo a un exclusivo grupo de personas, y, en segundo lugar, su razonamiento se encuentra limitado por razones de carácter institucional, no sólo procedimentales, sino también materiales, que no existen en el diálogo político o ciudadano. Pero a la vez, al contrario de lo que sucede, por ejemplo, en los debates parlamentarios, los jueces constitucionales tienen una mayor obligación de fundamentar sus decisiones, no sólo por el hecho de que forman parte del discurso judicial, donde su legitimidad se materializa a través de la argumentación, sino también porque estamos, en la mayor parte de las ocasiones, ante la última instancia en la resolución de un determinado problema jurídico ${ }^{33}$.

En cuanto a los elementos retóricos, las decisiones de los tribunales constitucionales tienen como destinatarios no sólo a las partes implicadas, sino también, y en especial en los denominados casos difíciles, a toda la comunidad política $\mathrm{o}$, en todo caso, a la mediática. Esto supone que sus decisiones contribuyen a estabilizar el debate político y moral, por lo que los discursos jurídicos elaborados por los tribunales constitucionales deben, en la medida de lo posible, evitar términos, teorías y razones muy formalistas, tecnicismos jurídicos y sentencias demasiado extensas que dificulten su comprensión. Por lo tanto, conviven dos maneras de entender la argumentación constitucional que Rawls definió en dos momentos de su obra: el equilibrio reflexivo (Rawls, 1978) y el consenso por solapamiento (Rawls, 1993).

El primero se caracteriza por la coherencia y corrección moral y el segundo se centra en el propósito de alcanzar acuerdos que, aunque no resuelvan el problema de fondo, facilitan la convivencia de la comunidad política que se encuentra dividida en cuestiones políticas, morales o ideológicas ${ }^{34}$. La cuestión, por tanto, radica en determinar cómo integrar estos dos tipos de razonamientos

33 Atienza (2007), p. 200.

34 Atienza (2007), p. 221. 
(la moral y el pragmatismo). Atienza, en este sentido, afirma que, cuando nos encontremos frente a la tutela de derechos fundamentales, deberían prevalecer los criterios de corrección, mientras que el pragmatismo tendría una mayor relevancia en cuestiones, por ejemplo, de competencia ${ }^{35}$.

\subsection{La ICC en el modelo principialista de control de constitucionalidad de las leyes}

La práctica de la totalidad de los teóricos del Derecho clasifica las normas jurídicas entre principios y reglas, a las cuales asigna una determinada forma de interpretación: la subsunción y la ponderación, respectivamente. Como hemos mencionado con anterioridad, la ICC constituye una técnica de interpretación que tiene la finalidad de evitar en abstracto la constitucionalidad de una norma infraconstitucional. Esta afirmación supone que la ICC no aplica en los juicios de constitucionalidad en concreto ${ }^{36}$, es decir, sólo opera cuando la norma infraconstitucional plantea un problema de constitucionalidad con una regla o reglas constitucionales, tanto expresas como implícitas o adscritas a una disposición de derecho fundamental ${ }^{37}$.

\footnotetext{
35 AtienZA (2007), p. 221.

36 No obstante, debe advertirse que la caracterización de los conflictos constitucionales como conflictos en concreto viene siendo discutida por parte de los teóricos del derecho. Véase MarTínez (2007), pp. 123 y ss. Entiende el autor citado que gran parte de los conflictos constitucionales resueltos a través de la ponderación son, en muchos casos, conflictos en abstracto. Así, el autor, a modo de ejemplo, ilustra el caso en que un sistema jurídico contemple dos normas: una que prohíba circular con el semáforo en rojo y otra que prohíba detenerse en una zona militar. El hecho real de que un conductor se encuentre ante un semáforo en rojo en una zona militar (antinomia parcial-parcial) no es necesario para que se produzca el conflicto normativo. Incluso, en el caso de que no exista ningún semáforo ubicado en una zona militar, esto no eliminaría el problema teórico (abstracto). Además, tenemos otro tipo de conflictos normativos, las antinomias contextuales, que también deben catalogarse como conflictos en abstracto: se manifiestan cada vez que aparece un caso genérico con modalidades deónticas incompatibles de comportamientos lógicamente independientes y existe una acción individual subsumible simultáneamente en ambos comportamientos. Este tipo de antinomias son las que suelen acontecer en los conflictos constitucionales, como, por ejemplo, entre la libertad de expresión y el derecho al honor; cada vez que aparece una acción individual que puede catalogarse simultáneamente en ambos derechos, con independencia de otras condiciones empíricas, estaremos ante un hecho que está simultáneamente prohibido y permitido y no ante casos de imposibilidad empírica de llevar a cabo todos los comportamientos ordenados por el sistema. No obstante, esta comprensión de los conflictos normativos no afecta a nuestra caracterización de la ICC como una interpretación en abstracto, en el sentido de precisar un texto normativo comprendido o reconstruir una determinada institución jurídica.

37 En el mismo sentido, DA SIIVA (2005), p. 12. Aquí también deben incluirse las reglas que los partidarios del juicio constitucional de proporcionalidad denominan como fines legítimos constitucionales, es decir, si se trata de un interés o bien legitimado constitucionalmente y si el órgano estatal que actúa tiene la competencia atribuida en esta materia. KLUTH (2005), pp. 441 y ss.
} 
Sin duda, la ICC resulta de especial ayuda para determinar el contenido normativo de enunciados jurídicos descritos con términos vagos o ambiguos. Así, podemos distinguir la vaguedad por "gradiente", donde el texto normativo contiene un término que hace referencia a una propiedad que se da en la realidad en distintos grados. Otro tipo de vaguedad es la "vaguedad combinatoria", en la que el término no se define por una serie de propiedades necesarias y suficientes, sino por un conjunto de propiedades relevantes, es decir, que sólo resulta necesario que el objeto presente un número relevante de estas propiedades. En tercer lugar, tenemos la vaguedad por "textura abierta" que hace referencia a objetos que, si bien eran previsibles a la hora de elaborar el texto normativo, de hecho, no fueron previstos. En cuarto lugar, tenemos las normas que contienen términos "esencialmente controvertidos", en los cuales la ambigüedad no se da en el contenido normativo (prohibición o el mandato), sino en el contenido específico o, en otras palabras, en los casos concretos que se aplica. Así, la prohibición de tratos crueles e inhumanos constituye un término esencial controvertido: existe consenso en prohibir este tipo de castigo, pero la discrepancia se produce respecto de cuán duro o desagradable debe ser un castigo para ser catalogado como cruel e inhumano ${ }^{38}$.

En el caso de que la aplicación de una norma infraconstitucional plantee un conflicto entre principios, su carácter abierto resulta estructural y la manera de determinarlo es a través de su interacción con otros principios. Entonces, como hemos manifestado, la ICC sólo sería aplicable a normas infraconstitucionales que, a la hora de controlar su constitucionalidad, deba cotejarse su contenido normativo con el establecido en una regla constitucional. Desde otra perspectiva y relacionado con la anterior afirmación, podríamos también afirmar que la ICC sólo es predicable en la interpretación subsuntiva, ya que ésta es un mecanismo de aplicación de las reglas, en contraposición con la interpretación ponderativa, que sólo es aplicable a los principios. Aquí, la subsunción no es vista como la aplicación de una norma a un caso concreto, sino la precisión de significado de esta norma a través la aplicación de las condiciones establecidas en una norma constitucional. Ahora bien, tanto en la ICC como en la ponderación se introduce un elemento condicionante en la norma infraconstitucional que, en el caso de esta última, son las denominadas normas adscritas a una disposición de derecho fundamental.

\footnotetext{
38 FerReres (2007), pp. 23-29. Waldron establece en los casos de los conceptos controvertidos, además de lo anteriormente señalado, las siguientes características: (1) la disputa se produce en los casos centrales o paradigmáticos que, además, (2) forman parte de la esencia del concepto, y (3) el desacuerdo en la aplicación del concepto es indispensable para que éste sea útil. WALDRON (1994), p. 530.
} 
No obstante, el juicio de proporcionalidad ${ }^{39}$ no debe ser visto como un sistema totalmente alternativo a la subsunción, sino que, a juicio de parte de la doctrina, éste opera en fases distintas.

Cuando existe una colisión entre principios, el paso previo al juicio de proporcionalidad consiste en determinar si la norma persigue una finalidad constitucionalmente ilegítima, en otras palabras, establece a través de un proceso subsuntivo si la ley viola una prohibición (regla) constitucional.

Posteriormente, la ley debe subsumirse prima facie tanto en el derecho o bien constitucional que protege, como en el derecho o bien fundamental que limita.

Superada la antinomia prima facie entre principios a través del principio de proporcionalidad, se produce una regla (norma adscrita a una disposición de derecho fundamental) que funciona, como hemos señalado, como un elemento condicionante en la normativa infraconstitucional y que se aplicará a través de un proceso de subsunción y de una coherente aplicación del precedente a casos futuros semejantes. Incluso puede suceder que el Tribunal Constitucional, tras establecer o descubrir una norma implícita, se vea compelido con posterioridad a realizar una interpretación de una norma infraconstitucional conforme con la norma constitucional adscrita.

La utilización de la ICC no plantea especiales problemas tanto en la determinación de si la norma infraconstitucional persigue un fin constitucionalmente ilegítimo como en la delimitación del contenido normativo de ésta conforme con una norma adscrita. Pero, sin embargo, debemos preguntarnos si la ICC resulta aplicable a la hora de adscribir prima facie la norma a una disposición de derecho fundamental. Se trata de determinar si la norma objeto de control de constitucionalidad lesiona un derecho que puede incluirse dentro del ámbito normativo de una disposición de derecho fundamental. Esta adscripción prima facie tiene como finalidad determinar el ámbito de protección inicial de una disposición de derecho fundamental.

De acuerdo con Bernal Pulido, el método literal representa el criterio capital para la adscripción prima facie de una norma a una disposición de derecho fundamental. Pero lo más destacable de este proceso de adscripción reside en el hecho de que el intérprete puede acudir a otras fuentes del Derecho, a saber, los tratados internacionales, la propia jurisprudencia del TC, la ley y las demás fuentes del Derecho en las cuales tengan cabida las normas y posiciones de derecho fundamental. El criterio de este método interpretativo de adscripción

39 Aquí, tomamos como referencia la compresión de la ponderación por parte de la doctrina y jurisprudencia alemana, española y chilena. Respecto del Derecho alemán y español véase la jurisprudencia y doctrina citada en BERNAL (2005), pp. 591-800. Respecto del Derecho nacional véase ARNOLD et al. (2012), pp. 65-112. 
prima facie es el siguiente: la circunstancia de que una norma o una posición esté tipificada en una fuente de los derechos fundamentales constituye una razón para su adscripción prima facie en la disposición o texto constitucional. Desde un punto de vista metodológico, se parte de una interpretación amplia del supuesto de hecho de las normas iusfundamentales directamente estatuidas. Así, toda norma legislativa que presente una propiedad, considerada aisladamente, subsumible en una disposición de derecho fundamental, debe ser considerada prima facie como parte de este derecho fundamental ${ }^{40}$. Incluso en los casos difíciles, donde no suele haber claridad acerca de si una propiedad debe incluirse en el supuesto de hecho de una disposición iusfundamental, debe también considerarse prima facie como parte de éste. Para determinar esta propiedad se parte de una interpretación analítica que establece el nexo semántico entre la norma o posición que es planteada en el control de constitucionalidad y los conceptos incluidos en las disposiciones de derecho fundamenta ${ }^{41}$. Ahora bien, debemos tener presente que estas definiciones no parten exclusivamente de premisas de índole analítica, sino también de antecedentes de carácter cultural, es decir, de usos paradigmáticos de conceptos incluidos en las disposiciones de derecho fundamental; de datos empíricos, es decir, de intervenciones en los derechos fundamentales pasadas o futuras, y con definiciones aportadas por las teorías externas de los derechos fundamentales ${ }^{42}$.

Como podemos apreciar, la determinación prima facie del conflicto constitucional constituye un proceso de interpretación en el que debe subsumirse la norma o posición de derecho fundamental en la disposición o texto estatuido en la Constitución. Entonces podría afirmarse que, como consecuencia de los principios in dubio pro libertaten y de efectividad de los derechos fundamentales, los tribunales constitucionales realizan una suerte de ICC o interpretación orientada a la Constitución de las normas infraconstitucionales. Ahora bien, en estos casos los tribunales constitucionales no adscriben una condición de aplicación o lo suprimen de manera definitiva, sino, precisamente, prima

\footnotetext{
40 Alexy (2007), p. 321.

41 Así, por ejemplo, una interpretación analítica que adscribe prima facie una norma a una disposición de derecho fundamental es aquella que, por ejemplo, adscribe al art. 19. $5^{\circ} \mathrm{CPR}$ ("La inviolabilidad del hogar y de toda forma de comunicación privada. El hogar sólo puede allanarse y las comunicaciones y documentos privados interceptarse, abrirse o registrarse en los casos y formas determinados por la ley") el artículo 206 CPP, que permite "la entrada y registro en lugares cerrados sin autorización u orden previa, cuando concurran signos evidentes indicaren que en el recinto se está cometiendo un delito". A partir de la locución "entrada y registros en lugares cerrados", la citada norma se adscribe prima facie al art. $19.5^{\circ} \mathrm{CPR}$.

42 Bernal (2005), pp. 628-629.
} 
facie. Por tanto, la ICC no resulta aplicable a la adscripción prima facie de una norma infraconstitucional ${ }^{43}$.

En conclusión, la ICC es predicable -más que a la estructura de las normas (principios o reglas), ya que en ambos es posible una interpretación de una norma infraconstitucional conforme con la Constitución- a los métodos o formas de interpretación, como un medio de concretar el proceso subsuntivo. Debe tenerse presente que la ICC es tanto una forma de interpretación como un medio de control de constitucionalidad. Así, cuando elimina o añade una o más condiciones de aplicación a la norma infraconstitucional, la determinación de estas condiciones y su adecuación a las condiciones de la norma constitucional constituyen el proceso de interpretación (y construcción del Derecho); mientras que el control de control de constitucionalidad se manifiesta en la estructura condicional de la sentencia. Esta estructura es meramente condicional o suficiente cuando estamos ante una ICC negativa (la norma N1 es constitucional si se elimina la propiedad p1 a la norma N1), o binominal o necesaria cuando estamos ante una ICC positiva (la norma N1 es constitucional sólo si se añade la propiedad p1 a la norma N1).

\section{El encaje de la ICC en las teorías de la interpretación constitucional}

La interpretación constitucional puede afrontarse a través de los tres grandes paradigmas teóricos: el modelo analítico o formalista, el modelo hermenéutico y el modelo alternativo ${ }^{44}$.

El modelo analítico nos aporta una correctividad de las operaciones deductivas a través de los recursos tradicionales de la lógica o a través de las reglas del lenguaje ${ }^{45}$. Su principal preocupación reside en señalar y resolver los problemas de vaguedad, ambigüedad e indeterminación que se producen en los lenguajes parcialmente tecnificados, como el del Derecho.

El modelo hermenéutico o sociológico da paso a otro tipo de razonamientos de tipo cultural, institucional, histórico, económico, etc. La hermenéutica recoge la tradición humanista del comentario de textos, con la ciencia de la cultura en

\footnotetext{
43 Una cuestión interesante de la incidencia de la ICC en el juicio o principio de proporcionalidad es que la determinación de una específica ICC puede incidir en la determinación de los principios en los conflictos. El TC, a la hora de dotar un contenido normativo condicional a una norma infraconstitucional, es decir, al incluir o añadir una condición, puede descubrir o construir un conflicto entre principios, cuestión sugerida por Álvaro Núñez en el Seminario Austral de Derecho.

44 Respecto de la denominada interpretación tópica debemos desecharla de nuestro objeto de estudio, ya que, al centrarse en resolver el caso concreto a través de una suerte de ensayo y error, rechaza cualquier tipo de interpretaciones en abstracto que limiten de alguna manera la resolución de casos futuros.

45 También puede encuadrarse en esta tradición el denominado convencionalismo semántico, es decir, la determinación de significados a través del estudio del quehacer cotidiano de los juristas.
} 
términos de Häberle ${ }^{46}$. Los textos normativos no irradian de manera completa y autosuficiente su contenido normativo, sino a partir de una "precomprensión" del intérprete sobre el contexto donde se plantea el problema jurídico. Ahora bien, la posición hermenéutica no debe equiparse con un subjetivismo radical, ya que con el proceso de precomprensión no sólo confluyen las circunstancias del sujeto que interpreta de acuerdo a su propia historicidad y contexto. Así, junto a las circunstancias del intérprete, deben añadirse las circunstancias históricas, sociológicas, económicas e institucionales en el proceso de interpretación constitucional de la ley y de la propia Constitución ${ }^{47}$. Desde otra perspectiva, aporta las circunstancias que quedaron fuera del proceso deductivo (analítico).

El modelo hermenéutico, con independencia de si consideramos una teoría adecuada para afrontar la interpretación de las normas jurídicas, se presenta de forma expresa o latente en las fundamentaciones de las sentencias de los tribunales constitucionales, lo que resulta evidente. Si partimos del hecho de que la adecuación de un precepto legal a la Constitución por vía interpretativa trata de conciliar los principios de supremacía de la Constitución y de conservación de la ley, entonces las vías de solución de este conflicto resultan difíciles de alcanzar si no acudimos a razonamientos de corte institucional, cultural, etcétera ${ }^{48}$.

Especial relevancia tienen en la interpretación constitucional las circunstancias extrajurídicas que introducen la idea de diálogo con aquellas instituciones que se hacen cargo de este tipo de razonamientos (el Parlamento, gobierno, tribunales ordinarios y, en general, la ciudadanía). La interpretación institucional, considerada como parte del modelo hermenéutico, busca armonizar el

\footnotetext{
46 HäberLe (2000), pp. 1-161.
}

47 LÓPEZ (2004), pp. 50 y ss. Comprensiones hermenéuticas sobre la interpretación constitucional. Podemos mencionar la propuesta de Hesse a través de cinco principios: el de unidad de la Constitución, el de concordancia práctica, el de corrección funcional, el de eficacia integradora y el de fuerza normativa de la Constitución. En la cultura anglosajona, Dworkin incluye criterios narrativos con una finalidad de integridad o consistencia textual, donde el intérprete constitucional se enfrenta a un contenido normativo delimitado por la práctica jurídica que trata de adecuar a las circunstancias presentes. Así, López entiende que las formas interpretativas de decisión (ICC y sentencias aditivas) deben hacer compatible el acervo recibido de las circunstancias coyunturales, manteniendo, de esta manera, la coherencia del sistema jurídico. López (2004), pp. 60 y ss.

48 Un ejemplo de la insuficiencia del modelo analítico podemos encontrarlo en las sentencias interpretativas que colman una laguna axiológica a través del principio de igualdad. Así, véase la STC español 222/1992, de 11 de diciembre, donde el TC amplió la facultad de subrogación en el contrato de arrendamiento, establecida en la antigua Ley de Arrendamientos Urbanos, en el caso de fallecimiento de un conviviente (unión de hecho). El modelo analítico se encuentra en dificultades a la hora de justificar este tipo de decisiones, salvo que a partir de una concepción convencionalista del lenguaje se entienda que el término "conviviente" incluye también las uniones de hecho. Por tanto, sólo quedaría la opción de declarar la inconstitucionalidad del precepto, situación que dejaría una situación de grave inseguridad jurídica y de desprotección al cónyuge supérstite. López (2004), p. 41. 
carácter vinculante de la Constitución con las funciones encomendadas a otras instituciones del Estado. Así, este diálogo se puede conceptualizar a través del principio de corrección funcional que puede aplicarse de manera expresa o latente en las decisiones de los tribunales constitucionales.

El substrato institucional en la jurisprudencia del TC opera en doble sentido: puede aparecer en la propia interpretación, ya sea como proceso o como resultado, y en la gestión de las consecuencias del resultado interpretativo, por ejemplo, respecto del impacto económico de la sentencia constitucional. En primer lugar, las relaciones institucionales tienen una incidencia previa a la hora de determinar no sólo el contenido de la decisión, sino también el tipo o clase de sentencia. Una de las razones que llevan a los tribunales constitucionales a optar por una sentencia interpretativa reside en buscar un determinado efecto sobre otras instituciones (el legislador o los jueces ordinarios). Esto supone que la aplicación lógica de los preceptos constitucionales formalmente invocados no constituye el único fundamento de sus fallos. En segundo lugar, en cuanto a la gestión de las consecuencias, dictada la sentencia, se pasa a comprobar su impacto en el resto del entramado institucional ${ }^{49}$. Así, podemos mencionar, entre otras, la incidencia económica y presupuestaria de un fallo de nulidad (aunque una sentencia interpretativa también puede suponer un gasto de recursos públicos); la inseguridad jurídica ocasionada como consecuencia del vacío normativo provocado por la sentencia de nulidad, y la mayor o menor complejidad en la reparación de la inconstitucionalidad ${ }^{50}$.

La interpretación alternativa se caracteriza por fundarse en la realidad social existente: el análisis de la realidad constitucional predomina sobre el de la normatividad constitucional. Desde un punto de vista axiológico, postula una interpretación judicial orientada a la tutela de los intereses de los menos favorecidos ${ }^{51}$. En los países de tradición jurídico-continental (civil law), las decisiones interpretativas despiertan intensas discusiones y reparos, debido a que en la cultura jurídica de estos países todavía se rechaza formalmente la capacidad de transformación de la sociedad mediante la interpretación judicial.

Dentro del modelo alternativo, debemos mencionar el paradigma deconstructivista, auspiciado, entre otros, por la Critical Legal Studies. Frente a las tesis constructivistas, como la hermenéutica tradicional, que confían en la consolidación de los significados mediante el contexto de la interpretación y el diálogo entre los intérpretes, esta corriente rechaza o se muestra escéptica respecto de la

49 LÓPEZ (2004), p. 9.

50 LóPez (2004), p. 419.

51 Véanse, entre otras, las últimas contribuciones a esta teoría: SANín (2014), pp. 1-219; CABO (2014), pp. 1-119. 
transmisión objetiva de sentido. El contexto impide una construcción neutral de sentido. Por el contrario, sirve al intérprete y aplicador del derecho para detectar o denunciar el estatus privilegiado de conceptos estables (representaciones sociales o topoi), que vienen proporcionados por la tradición o por la autoridad y que poseen per se un valor argumentativo (performativo) con su sola mención en los textos. A partir de una desconstrucción de los discursos jurídicos, este modelo plantea una interpretación alternativa como un medio de reforma política ${ }^{52}$.

La ICC es considerada como una manifestación del postulado coherentista de la hermenéutica; en cambio, la aproximación deconstructivista, al cuestionar el proceso de interacción de textos como fuente de consolidación de significados, negaría el poder de esta técnica basada en la extracción de un significado a partir de la conexión entre el texto legal y el constitucional ${ }^{53}$. En todo caso, el modelo deconstructivista no parece postular en último término una teoría general sobre la interpretación jurídica, sino más bien una forma alternativa (conflictivista) del modelo hermenéutico.

Abogamos, en este sentido, por una aproximación coherentista limitada y crítica de la interpretación jurídica que resulta aplicable a la interpretación constitucional y, en concreto, a la ICC. Esta aproximación, si bien acepta la interacción de textos como medio para consolidar los significados o el contenido normativo de un enunciado jurídico, entiende que parte de éste tiene su explicación en las relaciones de poder. Así, este contenido de poder (irracional) exige o demanda una interpretación de la ley conforme con la Constitución que cumpla una función de garantía y límite al poder del Estado, así como de transformación social. Pero, a la vez, la dogmática de los derechos fundamentales y de los principios y límites penales, entre otras, asentadas en los métodos analítico y hermenéutico de la interpretación, constituye un esfuerzo de racionalización del derecho. Si se entiende la interpretación del Derecho positivo como contención y filtro de la irracionalidad del poder del Estado, resulta necesario un sistema, entendido éste como la unidad de diversos conocimientos bajo una idea ${ }^{54}$.

\section{La autonomía conceptual de la interpretación conforme con la Constitución: la interpretación orientada a la Constitución}

Quizá una de las cuestiones más relevantes que surge en una primera aproximación de la ICC estriba en diferenciarla del resto de las decisiones del TC, ya que, si éste constituye en nuestro sistema constitucional el máximo intérprete

52 Derrida (1992), pp. 139-141; Balkin (1992), pp. 1986-1987.

53 LÓPEZ (2004), p. 131.

54 En el mismo sentido respecto a la necesidad de una teoría del delito como límite al poder punitivo, ZAFFARONI (2002), p. 376. 
de la Constitución, entonces todos sus fallos deben entenderse como formas de interpretación "conforme a la Constitución". En realidad, si entendemos que las normas que integran el sistema jurídico son "enunciados interpretativos", el término "sentencia interpretativa" carece de sentido, porque en cualquier razonamiento se configuran enunciados normativos (significados) diferentes del soporte lingüístico expresado en las disposiciones escritas.

La diferencia pareciese gravitar en el resultado: la ICC añade o expulsa un significado, mientras que las sentencias estimatorias de inconstitucionalidad expulsan textos normativos. Tampoco toda sentencia que contenga una o varias interpretaciones posibles de la ley de acuerdo a la Constitución puede catalogarse como una sentencia interpretativa en el sentido que habitualmente se le brinda a esta variante de sentencia manipulativa. Si el criterio determinante para identificar este tipo de sentencias fuera la existencia o no de interpretaciones de las normas infraconstitucionales, este tipo de sentencias carecerían de autonomía conceptual, ya que todas las sentencias del TC en mayor o menor medida realizan una interpretación de una ley. Por tanto, su peculiaridad reside en establecer "factores interpretativos condicionantes" ${ }^{55}$. Un claro ejemplo en nuestra jurisprudencia constitucional lo encontramos en la citada STC relativa al artículo 317 del CP, donde se establece expresamente, como condición para mantener este precepto vigente, una interpretación que respete el principio de culpabilidad (tipicidad subjetiva ${ }^{56}$. Por tanto, la ICC constituye tanto una forma de interpretación como una técnica de control de constitucionalidad. En cuanto a esta última, estamos ante una selección de normas una vez que éstas ya se encuentran interpretadas, que puede consistir en la expulsión de un contenido normativo o, además, en la atribución de uno nuevo: el TC decide sobre aquella interpretación que mejor se adecua al sistema de valores de la Constitución. Constituye una decisión intermedia ${ }^{57}$ entre declarar la validez de la ley de manera completa o expulsarla del ordenamiento jurídico, ante una modificación del contenido normativo sin expulsión del texto o disposición normativa ${ }^{58}$. La ICC, como técnica de control de constitucionalidad, ostenta, en virtud del principio de conservación de las normas, una primacía respecto

\footnotetext{
55 Carpio (2008), p. 162.

56 STC, rol 1584, de 31 de diciembre de 2009.

57 Otras decisiones intermedias que podemos mencionar son las denominadas recomendaciones al legislador o la declaración de constitucionalidad de la ley, pero dejando explícitamente abierta la posibilidad de un ulterior control a la luz de nuevos argumentos y datos. Pero, sin duda, la principal decisión intermedia en nuestro sistema procesal constitucional es el requerimiento de inaplicabilidad en sentido estricto, es decir, en aquellos casos en que la ley en términos constitucionales es válida, pero que en otros puede ser inconstitucional.
}

58 LÓPEZ (2004), p. 132. 
de los juicios o tests destinados a determinar la posible inconstitucionalidad de una ley: el TC, antes de plantearse la inconstitucionalidad de una norma, deberá establecer si resulta posible realizar una ICC ${ }^{59}$.

Como forma de interpretación, desde una tradición hermenéutica, estamos ante una modalidad de interpretación sistemática, una delimitación del contenido normativo de las leyes infraconstitucionales de acuerdo a lo establecido en la Constitución. De acuerdo con Benelli, y a modo de resumen, los criterios para calificar una sentencia como interpretativa son: (1) que la disposición impugnada tenga diversos significados; (2) que entre ellos existan sentidos hermenéuticos compatibles e incompatibles con la Constitución; (3) que la opción de interpretar la disposición sea el elemento constitutivo y condicionante de la decisión de no expulsar la disposición del ordenamiento jurídico ${ }^{60}$.

Por último, la ICC puede consignarse en el fallo o derivarse de los propios fundamentos de la sentencia. Incluso podemos encontrar casos en que el TC no realiza ninguna mención expresa a un condicionamiento interpretativo de la ley sometida al control de constitucionalidad, sino que se deriva de la lectura del texto del fallo y que de algún modo los operadores jurídicos entienden como vinculante ${ }^{61}$.

\subsection{Interpretación conforme con la Constitución versus la interpretación orientada a la Constitución}

Como hemos mencionado en la introducción de este estudio y, de acuerdo con el TC español, podemos distinguir deónticamente dos tipos de ICC: la declaración de constitucionalidad en la medida en que se interprete en el sentido que el TC considere adecuado, o no se interprete en el sentido (o sentidos) que considera inconstitucionales ${ }^{62}$. Por lo tanto, estamos ante dos resultados interpretativos: el negativo, que suele coincidir con la comprensión más generalizada de la ICC, y el positivo, también denominado como interpretación orientada a la Constitución (en lo sucesivo IOC). El primero establece, entre varias interpretaciones posibles, aquellas que resultan incompatibles con la Constitución. Así, deben existir varias posibilidades interpretativas, de las cuales, al menos, una conduce a la conformidad de la norma con la Constitución y, por lo menos, otra,

\footnotetext{
59 Véase que, de acuerdo con nuestro sistema procesal constitucional, la vía principal para llevar a cabo esta interpretación es el requerimiento de inaplicabilidad, que supone una contradicción entre el carácter concreto e incidental atribuido a éste y el carácter abstracto de la ICC, que supone que esta interpretación debe ser aplicada a todos los casos futuros.

60 Benelli (2002), p. 1275.

61 LÓPEZ (2004), p. 5.

62 STC 5/1981, de 13 de febrero, FJ 6.
} 
a la inconstitucionalidad. Para este caso, el mandato de la interpretación indica que no hay que escoger ninguna de las interpretaciones inconstitucionales, sino una de las que son conformes a la Constitución ${ }^{63}$.

La IOC establece qué interpretación respeta en mayor medida el contenido normativo de la Constitución ${ }^{64}$ : exige tener en cuenta las normas constitucionales a la hora de elegir entre diversas variantes interpretativas ${ }^{65}$. Aquí el mandato opera como principio, ya que la mayor adecuación a la Constitución puede tener un mayor o menor peso entre las varias posibilidades interpretativas. En cambio, el mandato negativo tiene la estructura de una regla, puesto que obliga estrictamente a rechazar las posibilidades interpretativas inconstitucionales a favor de las que lo son conforme a ésta ${ }^{66}$. En la IOC, por tanto, todas las interpretaciones son compatibles con la Constitución, pero el intérprete deberá escoger aquella que contribuya en mayor medida a la aplicación de las normas constitucionales. Parte de la doctrina comparada establece una diferencia entre la ICC positiva y la IOC en el hecho de que la primera sólo obliga a declarar la existencia de una o más interpretaciones de la norma que no vulneran la Constitución. No obstante, y adelantándonos a una de las conclusiones de este estudio, entendemos que no existe una diferencia estructural entre la IOC y la ICC en su dimensión positiva, sino una institucional: la conveniencia de que determinadas interpretaciones conforme la Constitución las realice el TC y, por el contrario, otras, los tribunales ordinarios de justicia.

Desde la perspectiva de los tribunales ordinarios, por tanto, resulta importante determinar si los tribunales constitucionales deben limitarse a rechazar determinadas posibilidades interpretativas por inconstitucionales y señalar sólo que es posible una ICC, dejando a éstos su concreción; o, por el contrario, establecer una ICC positiva o IOC como factor condicionante. Si entendemos que resulta viable esta última posibilidad, el TC, al establecer normalmente una sola interpretación, excluiría otras futuras opciones interpretativas por parte de los tribunales ordinarios ${ }^{67}$. En todo caso, debemos señalar que nuestra praxis

63 KUHLEN (2012), p. 24. Por ejemplo, véase la interpretación que realiza el TC respecto del art. 317 CP, donde, tras declarar inconstitucional una interpretación meramente causal de este delito cualificado por el resultado, estableció que "la única interpretación constitucionalmente admisible del precepto legal cuya aplicación se impugna es aquella que exige la concurrencia de elementos subjetivos para agravar la pena respectiva conforme al art. 317 CP". STC, rol 1584, de 31 de diciembre de 2009.

64 SiLVA (2012), p. 14.

65 KUHLEN (2012), p. 25.

66 Kuhlen (2012), p. 25.

67 Otro supuesto distinto es cuando se encuentra ante varias interpretaciones, todas ellas conforme con la Constitución. Para una gran parte de la doctrina y jurisprudencia nos encontramos ante un supuesto de mera legalidad que corresponde resolver a los tribunales ordinarios. 
jurisprudencial, al menos en el orden penal, viene estableciendo como factor condicionante una determinada interpretación del precepto sometido al examen de constitucionalidad ${ }^{68}$.

Para López la diferencia entre la ICC y la IOC reside, en primer lugar, en que en esta última participan todos los intérpretes, mientras que la primera sólo puede ser aplicada por aquellos intérpretes que tienen la potestad de expulsar una norma del ordenamiento jurídico; $y$, en segundo lugar, porque la primera incluye un proceso de control de normas, cuya misión consiste en imponer un resultado hermenéutico sobre el resto de los intérpretes. Ahora bien, respecto de la primera diferencia, como manifiesta el autor citado, cuando más se abra la ICC a la comunidad política (por ejemplo, a los tribunales ordinarios), más se difumina esta diferencia ${ }^{69}$. En cuanto a la segunda diferencia, la imposición de una determinada interpretación también concurre, en mayor o menor medida, en los fallos de los tribunales ordinarios superiores a la hora de unificar la jurisprudencia de los tribunales inferiores.

A juicio de Kuhlen, la nota distintiva radica en la concurrencia o no de un rechazo o exclusión de una determinada variante interpretativa. Ahora bien, para el autor citado, en ambas modalidades se exige que el TC adopte una o varias de las interpretaciones de la norma infraconstitucional que resulten conformes con la Constitución. Los tribunales constitucionales no deben averiguar todas las interpretaciones plausibles conforme con la Constitución, sino que sólo deben establecer que una de ellas resulta inconstitucional y otra, por el contrario, conforme con ella. Ahora bien, resulta extraña esta afirmación, ya que todo intérprete a la hora determinar el contenido de un texto normativo suele establecer el mejor resultado interpretativo y no uno o varios que pueden ser conformes con la Constitución. Esto explica que la praxis jurisprudencial suela expulsar de la comunidad jurídica una determina interpretación y, a la vez, establecer la mejor interpretación del texto normativo conforme con la Constitución ${ }^{70}$.

El presupuesto sobre el cual se construye la ICC (la concurrencia de una o más interpretaciones conformes a la Constitución y una o más interpretaciones en contra de la Constitución) debe ser matizado si tomamos en cuenta que todo operador del Derecho debe interpretar los preceptos legales de acuerdo

68 SsTC, rol 1584-09, de 17 de junio de 2010; rol 1584-09, de 17 de junio de 2010; rol 739, de 21 de agosto de 2007, y rol 993, de 13 de mayo de 2008. En el derecho procesal penal, véanse las SsTC rol 1484, de 5 de octubre de 2010; rol 1337, de 20 agosto de 2009; rol 1380, de 20 de noviembre de 2009, ambas sobre los arts. 186 y 230 CPP.

69 LÓPEZ (2004), p. 133.

70 KUHLEN (2012), pp. 14 y ss. 
con la Constitución. Así, entre varios sentidos a priori atribuibles a una norma infraconstitucional debe acoger aquel que se adecue en mayor medida al texto constitucional, para así evitar que aquélla sea declarada inconstitucional ${ }^{71}$. Pero, entonces, la diferencia entre la ICC e IOC se difumina aún más, ya que los tribunales de justica superiores, al conocer los recursos sobre determinadas interpretaciones realizadas por los tribunales inferiores, pueden, y de hecho así lo hacen, rechazar una determinada interpretación con un argumento constitucional y establecer la que se adecua mejor al contenido normativo de la Constitución ${ }^{72}$. Un ejemplo paradigmático de esta situación la encontramos en la doctrina y jurisprudencia penal ordinaria, en las que resulta común realizar interpretaciones dogmáticas conforme u orientadas a la Constitución en las que se reduce o amplía el significado de los preceptos ${ }^{73}$.

La doctrina entiende que el límite a la interpretación constitucional por parte de los tribunales ordinarios se encuentra en el denominado "sentido literal posible". La elección entre varias posibilidades interpretativas jurídicoconstitucionalmente admisibles de acuerdo al sentido literal corresponde a los tribunales ordinarios y, en especial, a los tribunales superiores ${ }^{74}$, constituye una manifestación más del nuevo paradigma constitucional o neoconstitucionalismo. Para su determinación se puede acudir, junto a los métodos clásicos (histórico, sistemático y teleológico), a la IOC. Así, las variantes interpretativas entre las que hay que realizar una elección conforme a la Constitución son, precisamente, aquellas que son compatibles con el sentido literal posible. También se ha establecido como límite aquellas interpretaciones que se apartan claramente de la voluntad del legislador ${ }^{75}$.

71 Por todos, DA SiLVA (2005), p. 17.

72 Esta posibilidad resulta especialmente patente en la causal del recurso de nulidad contemplada en el art. 373 a) CPP.

73 Véase una última manifestación en la SCS (causa rol 4949-2015) que, a partir una comprensión de la teoría del bien jurídico y del principio de mínima intervención basado en fundamentos constitucionales, realiza una interpretación de los delitos de tráfico de drogas, donde, por una parte, expulsa de la comunidad jurídica un determinado contenido normativo (una determinada comprensión de los delitos de peligro abstracto), y realiza una interpretación alternativa, es decir, una IOC. Véase que los fundamentos de esta sentencia pueden trasladarse a los realizados en un fallo del TC. Véase en este sentido la STC rol 993, de 13 de mayo de 2008, relativa al delito de microtráfico.

74 KUHLEN (2012), p. 123.

75 Kuhlen (2012), p. 37. Respecto de las ICC que se apartan claramente de la intención del legislador, la jurisprudencia de la Corte Suprema estadounidense como es bien sabido, otorga una especial referencia a la voluntad del legislador (judicial restrain theory). Así, la Corte Suprema ha descrito el avoidance canon de la siguiente manera: "Donde una interpretación aceptable de la ley arroja serias dudas sobre su constitucionalidad, la Corte interpretará la ley de tal manera que evite [avoid] estas dudas, a no ser que tal interpretación sea claramente contraria a la intención del legislador". Edward J. 
Se puede correr el riesgo de que un tribunal ordinario dé prioridad a una interpretación remota de la norma que rebase el sentido literal posible, frente a una interpretación más plausible, pero valorada como inconstitucional. En estos casos surge la duda de si el tribunal ordinario se entromete de facto en una competencia del TC. Y, a la inversa, existe el peligro de que este último lesione la competencia de interpretación de los tribunales ordinarios, en la medida en que marque una de entre varias interpretaciones conformes a la Constitución como constitucionalmente obligada, en vez de limitarse a rechazar las posibilidades interpretativas inconstitucionales y dejar la elección a los tribunales ordinarios ${ }^{76}$.

Kuhlen establece dos grandes categorías en la ICC: la conformidad material y la conformidad formal con la Constitución de las interpretaciones de la ley. La primera categoría examina, principalmente, la adecuación de las posibles interpretaciones de la ley a tenor de los derechos fundamentales y en casos de un menoscabo gravemente desproporcionado. La tarea de examinar materialmente las interpretaciones judiciales corresponde, generalmente, a los tribunales constitucionales. Khulen mantiene que es una competencia que pertenece indiscutiblemente, en el caso alemán, al TC Federal77.

La conformidad formal con la Constitución examina la vinculación del juez al Derecho. Esta vinculación en el orden penal se manifiesta de manera especial con la prohibición de aplicar analógicamente las leyes penales en perjuicio del reo, no sólo en sentido estricto, sino también en sentido amplio, es decir, como cualquier aplicación del Derecho que vaya más allá del sentido literal posible ${ }^{78}$. Junto a la prohibición de analogía, la interpretación judicial de la ley penal está sometida al mandato de certeza. Este mandato, que se dirige especialmente al legislador, restringe también el círculo de las interpretaciones de la ley que son admisibles ${ }^{79}$.

Khulen establece dos tipos de relaciones entre las interpretaciones formales y materiales. La primera es cuando nos encontramos ante una interpretación plausible o dentro del sentido literal posible y la génesis de la norma, pero materialmente inconstitucional, es decir, cuando tampoco al legislador le estaría

DeBartolo Corp. V. Fla. Gulf Coast Bldg \& Constr. Trades Council, 485, U.S. 568, 575 (1988). Citado por BERRY (2012), p. 116. No obstante, como hemos visto con anterioridad ( $\left.N^{\circ} 4\right)$ una parte de la doctrina estadounidense entiende que, a partir de una comprensión de la avoidance doctrine como mecanismo de protección de normas constitucionales permite una interpretación de la ley incluso en contra de la voluntad del legislador expresamente establecida en ésta.

76 KUHLEN (2012), p. 39.

77 KUHLEN (2012), p. 77.

78 KUHLeN (2012), p. 78.

79 A favor de aplicar el mandato de determinación en la fase de interpretación KUHLEN (2012), pp. 78-79. 
permitido promulgar una norma en tales términos ${ }^{80}$. La segunda relación concurre cuando estamos ante una interpretación remota. En este caso, las interpretaciones pueden ser formalmente inconstitucionales de acuerdo con los mandatos derivados del principio de legalidad, porque superan los límites del sentido literal posible, aunque su promulgación no le está prohibida al legislador ${ }^{81}$. Como principio general, resulta obligatorio elegir, entre las interpretaciones conforme a la Constitución, aquella que resulta plausible de acuerdo con los métodos clásicos de interpretación, frente a las remotas. Se puede acudir a las interpretaciones remotas sólo cuando las interpretaciones plausibles son inconstitucionales ${ }^{82}$.

A partir de la interpretación plausible y remota conforme con la Constitución, Kuhlen establece un principio de autocontención interpretativa destinado tanto para los tribunales constitucionales como para los tribunales ordinarios. Respecto de estos últimos, deberían centrarse en determinar, dentro de los cánones clásicos de la interpretación, qué interpretación se adecua mejor al contenido de la Constitución; estamos ante la comprensión más usual de la IOC. En estos casos, la fundamentación constitucional serviría para incrementar la fuerza de convicción de la argumentación ${ }^{83}$. En cambio, los tribunales constitucionales sí estarían legitimados para rechazar determinadas interpretaciones plausibles dentro del sentido literal posible con una argumentación estrictamente constitucional y decantarse por otra interpretación remota. Este tipo de interpretaciones demandan un importante esfuerzo de argumentación con frecuencia, fuertemente valorativa ${ }^{84}$, que, además, daña la autoridad democrática de la norma ${ }^{85}$. Ahora bien, el autor citado no aboga por una prohibición absoluta de expulsar una interpretación plausible por ser contraria a la Constitución por parte de los tribunales ordinarios, sino por un principio de autocontención (institucional), es decir; sólo resulta recomendable en los casos en que parece "prácticamente seguro" que una determinada interpretación infringe la Constitución ${ }^{86}$. Pero a la vez, en cuanto a la elección de una determinada interpretación de la ley conforme con la Constitución dentro

80 KuHLeN (2012), p. 84.

81 KuHLeN (2012), p. 84.

82 KuHlen (2012), p. 90. Véase la jurisprudencia citada por el autor, p. 90, № 32.

83 Ésta parece ser la posición de Da Silva, que entiende la ICC como un criterio correctivo de una previa interpretación jurídica. Así, tras establecer el sentido del texto conforme con los criterios clásicos, deberá establecerse si éste resulta conforme con el texto constitucional. DA Silva (2005), p. 23.

84 El rechazo de una determinada interpretación por ser materialmente inconstitucional es, desde el punto de vista del contenido, más exigente, ya que requiere un importante esfuerzo de fundamentación, debido a la compleja, a lo que tendríamos que añadir "y confusa", dogmática de los derechos fundamentales.

85 KuHLEN (2012), p. 91 y $119-120$.

86 KuHLen (2012), p. 122. 
del sentido literal posible, es una tarea de los tribunales ordinarios y, en especial, de los tribunales superiores y, por tanto, aquí también opera un mandato de autocontención respecto de los tribunales constitucionales ${ }^{87}$.

Ahora bien, la propuesta del citado autor resulta problemática en varios sentidos. En primer lugar, resulta difícil establecer cuándo nos encontramos ante una interpretación de acuerdo al sentido de ley o ante una remota. Así, podemos encontrar numerosos ejemplos, al menos en el Derecho Penal, de interpretaciones remotas en la jurisdicción ordinaria y, en especial, en los tribunales superiores de justicia. En segundo lugar, la afirmación de que los tribunales ordinarios puedan expulsar un contenido normativo cuando exista una seguridad casi absoluta de que éste infringe una norma constitucional resulta problemática, porque ésta pareciese ser la función genuina del TC, de acuerdo con el propio principio de deferencia hacia el legislador democrático, a la hora de expulsar un contenido normativo con expulsión de texto: sólo puede expulsar o inaplicar una norma cuando sea claramente inconstitucional. Así, por ejemplo, tenemos el caso paradigmático del juicio o principio de proporcionalidad en sentido amplio, que requiere que la aplicación de la norma sea gravemente desproporcionada. Por lo tanto, también el TC debería de expulsar contenido normativo sin expulsión de texto cuando sea "prácticamente seguro" que una determinada interpretación infringe la Constitución.

Si tomamos en cuenta que la función de los tribunales constitucionales no radica en establecer el contenido óptimo de una ley o la interpretación más correcta conforme con la Constitución, sino en descartar aquellas que resultan claramente inconstitucionales, entonces podemos concluir que la interpretación negativa de la constitución constituye no sólo una opción intermedia entre la declaración de inconstitucionalidad y la IOC, sino también una opción preferente respecto de ésta. En otras palabras, de acuerdo con el principio de deferencia hacia el legislador y a los tribunales ordinarios, el TC debería sólo centrarse en declarar aquellas interpretaciones que resultan claramente contrarias a la Constitución, ya que, en la determinación de la mejor interpretación posible de acuerdo a la Constitución, corre el riesgo de asumir funciones legislativas o judiciales: puede de facto convertirse en una verdadera modificación de la ley o restringir la soberanía hermenéutica de los tribunales ordinarios ${ }^{88}$.

87 KUHLEN (2012), p. 123. Según la opinión dominante en la doctrina alemana, una ICC realizada por los tribunales ordinarios sólo es admisible en la medida en que el sentido literal posible y la génesis del precepto, más concretamente "la voluntad claramente reconocible del legislador", no se opongan a ella. Por todos, Kunlen (2012), p. 95.

${ }^{88}$ Así, Kuhlen critica la sentencia del Tribunal Constitucional alemán referida al caso del blanqueo de capitales por parte de abogados defensores, donde realizó una reducción teleológica del elemento típico "dolo", excluyendo el dolo eventual en cuanto al conocimiento de la procedencia del dinero. Al exigir 
Por tanto, los tribunales constitucionales pueden llevar a cabo una interpretación o desarrollo del derecho sólo cuando exista una variante interpretativa materialmente conforme con la Constitución ${ }^{89}$. Cuando existan varias posibilidades para conservar la norma, el TC solamente debe descartar aquellas que resultan contrarias a la Constitución, dejando a los tribunales ordinarios la concreta elección ${ }^{90}$. En cambio, cuando un tribunal ordinario y, en especial, los tribunales superiores eligen una de las posibles interpretaciones conformes con la Constitución no se atribuyen ilegítimamente una competencia, sino que ello pertenece a una de sus tareas genuinas ${ }^{91}$. Es más, si la norma infraconstitucional incide de manera directa en derechos fundamentales, como suele suceder con la mayor parte del Derecho Penal, unido con el principio de conservación de las leyes penales, las interpretaciones restrictivas de las leyes penales a través de fundamentaciones jurídico-constitucionales resulta no sólo posible, sino obligatoria. Como conclusión, el TC sólo debería acudir de manera excepcional a una interpretación positiva u orientada a la Constitución, siendo, por tanto, la interpretación negativa en sentido fuerte la regla general92. También resulta recomendable que el TC, a la hora de establecer el sentido de una ley, no se aparte de la interpretación o las interpretaciones que ya se encontraban presentes en la praxis jurisprudencial y se centre, como venimos repitiendo en este estudio, en expulsar aquellos contenidos normativos claramente contrarios a la Constitución. Desde el punto de vista institucional, los tribunales constitucionales deberían adoptar interpretaciones orientadas a la Constitución sólo

el dolo directo, el TC, a juicio del autor citado, se extralimitó en sus competencias en detrimento de la jurisdicción ordinaria y, por el contrario, éste debería haberse limitado a dibujar las líneas generales de las posibles interpretaciones o reducciones del art. 261 del Código Penal alemán que resulten conformes con la Constitución. KUHLEN (2012), pp. 35-38.

89 Kuhlen (2012), p. 100.

90 KuHlen (2012), pp. 100-101. El autor citado pone como ejemplo el fallo del TC alemán sobre la pena de prisión perpetua, donde se estableció una ICC obligada para los tribunales ordinarios: la no imposición de la pena de privación perpetua de libertad desproporcionada en el caso concreto. BVerfGE, 73, 206 (260). Pero aquí, más que una interpretación, estamos ante una obligación de aplicar un método de interpretación.

91 KUHLEN (2012), p. 112.

92 En cambio, Kuhlen se muestra a favor de que los tribunales constitucionales determinen la interpretación o interpretaciones conformes con la Constitución. La tensión con los tribunales ordinarios la resuelve a través del principio que denomina como de autocontención de los tribunales ordinarios en cuanto al recurso a la interpretación (o reducción teleológica) conforme a la Constitución. Por un lado, porque no resulta necesario, como ocurre con los tribunales constitucionales, acudir a los preceptos constitucionales para sostener una determinada interpretación, y, por otro lado, porque el recurso a la Constitución resulta más arriesgado y no añade necesariamente fuerza de convicción a una determinada opción interpretativa. KUHLEN (2012), p. 112. 
en los casos de pronunciamientos meramente declarativos en los que exista un consenso doctrinal y jurisprudencial.

Ahora bien, los tribunales ordinarios, en especial los tribunales superiores, a la hora de unificar la jurisprudencia pueden realizar ICC negativas. Un claro ejemplo lo encontramos en las causas de atipicidad penal fundamentadas en normas constitucionales. Llegados a este punto podemos concluir que no existe una diferencia estructural entre la ICC realizada por los tribunales constitucionales y la IOC atribuida a los tribunales ordinarios. Ambos pueden realizar interpretaciones conformes u orientadas a la Constitución, tanto en su dimensión negativa como positiva. Es más, estos último, y en especial los tribunales superiores, realizan interpretaciones negativas conforme con la Constitución que expulsan una determinada interpretación como factor condicionante de constitucionalidad.

\section{Conclusiones}

Este estudio, como se ha señalado en su introducción, ha pretendido realizar una aproximación conceptual, especialmente descriptiva, a la ICC, que sirva de fundamento para el establecimiento de unos criterios de interpretación, principalmente, de segundo orden, es decir, unas reglas que nos permitan justificar su uso como mecanismo de control de constitucionalidad.

Un primer criterio de interpretación está fundamentado en consideraciones estructurales e institucionales. En cuanto a las primeras, si consideramos la ICC como una interpretación en abstracto que sólo puede tomar como referencia reglas constitucionales, entonces estamos ante un proceso y resultado interpretativo en el control de constitucionalidad de las leyes previo al control concreto de constitucionalidad. En cuanto al fundamento institucional, el principio de conservación de las normas otorga una preferencia a la ICC respecto de los juicios de constitucionalidad, que tienen como consecuencia la declaración de inconstitucionalidad.

A partir del hecho de que no existe una diferencia estructural entre la ICC realizada por los tribunales constitucionales y la interpretación orientada hacia la Constitución realizada por los tribunales ordinarios, podemos establecer un segundo criterio de interpretación de segundo orden institucional: los tribunales constitucionales deben sólo centrarse en declarar aquellas interpretaciones que resultan claramente contrarias a la Constitución, ya que la determinación de la mejor interpretación posible de acuerdo a la Constitución corresponde a los tribunales ordinarios (superiores).

Un tercer criterio de interpretación recomienda que el TC, a la hora de establecer el sentido de una ley, no se aparte de la interpretación o las interpretaciones que ya se encontraban presentes en la praxis jurisprudencial y se 
centre, como venimos repitiendo en este estudio, en expulsar aquellos contenidos normativos claramente contrarios a la Constitución.

Con independencia de aceptar una suerte de autocontención, por una parte, del TC a la hora de realizar una ICC positiva, y, por otra parte, de los tribunales ordinarios a la hora de expulsar contenidos normativos de la comunidad jurídica con fundamento en normas constitucionales, resulta necesario establecer también criterios de interpretación que nos permitan determinar cuándo resulta razonable acudir a una ICC. Así, podemos destacar: (1) que el problema interpretativo se centre en la aplicación de normas constitucionales, (2) que estemos ante un denominado caso difícil y (3) y la necesidad de que una determinada interpretación de una norma de acuerdo con la Constitución, tanto positiva como negativa, ostente una mayor fuerza vinculante.

Un último criterio de interpretación, en este caso valorativo, establece que cuando la ICC se encuentre ante la tutela de derechos fundamentales deberían prevalecer los criterios de corrección, mientras que el pragmatismo tendría una mayor relevancia en cuestiones, por ejemplo, de competencia.

En cuanto al contenido material de la ICC, abogamos por una aproximación coherentista limitada y crítica de la interpretación jurídica. Esta aproximación, si bien acepta la interacción de textos como medio para consolidar los significados o el contenido normativo de un enunciado jurídico, entiende que parte de éste tiene su explicación en las relaciones de poder. Así, este contenido de poder (irracional) exige o demanda una interpretación de la ley conforme con la Constitución que cumpla una función de garantía y límite al poder del Estado, así como de transformación social.

\section{BiBLIOGRAFÍA CITADA}

Aldunate, Eduardo (2009): "La fuerza normativa de la Constitución y el sistema de fuentes del Derecho", en: Revista Chilena de Derecho (vol. XXXII), pp. 443-484.

AtienzA, Manuel (2007): "Constitución y argumentación", en: Anuario de Filosofía del Derecho $\left(\mathrm{N}^{\circ} 24\right)$.

AleXY, Robert (2007): Teoría de los derechos fundamentales, $2^{\text {a }}$ edición (Traducc. Carlos Bernal Pulido, Madrid, Centro de Estudios Constitucionales).

Arnold, Rainer; MartíneZ, José, y ZúÑIGA, Francisco (2012): “El principio de proporcionalidad en la jurisprudencia del Tribunal Constitucional", en: Estudios Constitucionales (vol. X, No 1). Disponible en: http://dx.doi.org/10.4067/ S0718-52002012000100003 [visitado el 12.10.2015].

BeNELLI, Filippo (2002): "Le sentenze interpretative e manipolative nel processo in via principale di ieri e di oggi: dai modelli (pregressi) alla dinamica 
(futura)", en: Le Regioni, (No 6). Disponible en: http://www.rivisteweb.it/ doi/10.1443/8487 [visitado el 10.06.2015].

Bernal Pulido, Carlos (2005): El principio de proporcionalidad y derechos fundamentales (Madrid, Centro de Estudios Constitucionales).

BALKIN, Jack M. (1992): "What is Postmodern Constitutionalism?", en: Yale Faculty Scholarship Series, Michigan Law Review (Paper 275). Disponible en: http:// digitalcommons.law.yale.edu/fss_papers/275 [visitado el 12.05.2015].

Cabo Martín, Carlos (2014): Pensamiento crítico, constitucionalismo crítico (Madrid, Trotta).

CARPIO MARCOS, Edgar (2008): "La interpretación conforme a la Constitución y las sentencias interpretativas (con especial referencia a la experiencia alemana)", en: Estudios en Homenaje a Héctor Fiz-Zamudio, Instituto de Investigaciones Jurídicas (Biblioteca virtual). Disponible en: http://biblio. juridicas.unam.mx/libros/6/2560/10.pdf [visitado el 12.05.2015].

Da SiLVA, Virgilio Alfonso (2005): "La interpretación conforme con la Constitución. Entre la trivialidad y la centralización judicial", en: Cuestiones Constitucionales. Revista Mexicana de Derecho Constitucional ( $\left.\mathrm{N}^{\circ} 12\right)$.

DeRridA, Jacques. (1992): "Fuerza de ley: el fundamento místico de la autoridad", en: Doxa. Cuadernos de Filosofía del Derecho (№ 11), pp. 129-191.

FerReres Comella, Víctor (2007): Justicia constitucional y democracia, $2^{\text {a }}$ edición (Madrid, Centro de Estudios Constitucionales).

Gianformaggio, Letizia (1987): "Lógica y argumentación en la interpretación jurídica o tomar a los juristas intérpretes en serio", en: Doxa. Cuadernos de Filosofía del Derecho ( $\mathrm{N}^{\circ}$ 4) (Traducc. J.A. Pérez Lledó), pp. 90 y ss.

Guastinl, Ricardo (1999): Distinguiendo: estudios de teoría y metateoría del Derecho (Traducc. Jordi Ferrer Beltrán, Barcelona, Editorial Gedisa).

HäBERLE, Peter (2000): Teoría de la Constitución como ciencia de la cultura (Traducc. Emilio Mikunda, Madrid, Editorial Tecnos).

HART, Herbert (1997): El concepto de Derecho (Traducc. Genaro Carrió, Buenos Aires, Editorial Abeledo Perrot).

KUHLEN, Lothar (2012): La interpretación conforme a Constitución de las leyes penales (Traducc. Nuria Pastor, Madrid, Editorial Marcial Pons, Ediciones Jurídicas y Sociales).

KLUTH, Winfried (2005): "La prohibición de exceso y principio de proporcionalidad en el Derecho Penal alemán", en: Revista del Instituto Bartolomé de las Casas ( $\left.\mathrm{N}^{\circ} 8\right)$. 
Landa Arroyo, César (2005): "Interpretación constitucional y Derecho Penal", en: Anuario de Derecho Penal. Disponible en: http://perso.unifr.ch/derechopenal/assets/files/anuario/an_2005_06.pdf [visitado el 12/05/2015].

Lifante Vidal, Isabel (2015): "La interpretación jurídica", en: Enciclopedia de Filosofía y Teoría del Derecho (vol. II). Disponible en: http://biblio.juridicas. unam.mx/libros/libro.htm?l=3796 [visitado el 12/05/2015].

LÓPEZ BOFIIL, Héctor (2004): Decisiones interpretativas en el control de constitucionalidad de la ley (Valencia, Tirant lo Blanch).

MARTínez ZorrILLA, David (2007): Los conflictos constitucionales, ponderación e indeterminación normativa (Madrid, Marcial Pons).

MacCormick, Neil (1994): Legal Reasoning and Legal Theory (Oxford, Clarendon Press).

Nogueira, Humberto (2009): "Enfoque sobre interpretación constitucional y jurisdicción constitucional", en: Temas actuales de Derecho constitucional (Santiago, Asociación Chilena de Derecho Constitucional, Editorial Jurídica de Chile), pp. 155-186.

NúÑez Poblete, Manuel (2012): "Los efectos de las sentencias en el proceso de inaplicabilidad en Chile: examen a un quinquenio de la Reforma Constitucional", en: Revista de Estudios Constitucionales ( $\left.\mathrm{N}^{\circ} 10\right)$. Disponible en: http://www.cecoch.cl/docs/pdf/revista_10_1_2012/06\%20(015-064)\%20 LOS_EFECTOS.pdf [visitado el 12/05/2015].

NúÑez Vaquero, Álvaro (2014): "Kelsen en la encrucijada: Ciencia jurídica e interpretación del Derecho", en: Revista lus et Praxis (Año 20, № 2).

PICA Flores, Rodrigo (2012): Control jurisdiccional de constitucionalidad de la ley en Chile: los procesos de inconstitucionalidad y de inaplicabilidad por inconstitucionalidad de competencia del Tribunal Constitucional, $2^{\text {a }}$ edición (Santiago, Ediciones Jurídicas de Santiago).

Sanín Restrepo, Ricardo (2014): Teoría crítica constitucional (Valencia, Tirant lo Blanch).

Rollnert Liern, Göran (2014): "La mutación constitucional, entre interpretación y la jurisdicción constitucional", en: Revista Española de Derecho Constitucional ( $\left.\mathrm{N}^{\circ} 101\right)$, pp. 125-155.

Silva Irarrázabal, Luis Alejandro (2012): "Es el Tribunal Constitucional el máximo intérprete de la Constitución", en: Revista de Derecho de la Pontificia Universidad Católica de Valparaíso (vol. XXXVIII), pp. 573-616.

(2014): "La dimensión legal de la interpretación constitucional", en: Revista Chilena de Derecho (vol. XLI, № 2), pp. 439-471. 
Silva SÁnCHeZ, Jesús María (2012): "Presentación" en: Kuhlen, Lothar, La ICC a la Constitución de las leyes penales (Traducc. Nuria Pastor, Madrid, Editorial Marcial Pons, Ediciones Jurídicas y Sociales).

Sото KLoss, Eduardo (1996): Derecho administrativo: bases fundamentales (Santiago, Editorial Jurídica de Chile), tomo II.

Verdugo, Mario; Pfeffer, Emilio, y Nogueira, Humberto (1994): Derecho constitucional (Santiago, Editorial Jurídica de Chile), tomo I.

WALDRON, Jeremy (1994): "Vagueness in Law and Language: Some Philosophical lusses", en: California Law Review (№ 509).

WRóBLEWSKI, Jerzy (1985): Constitución y teoría general de la interpretación jurídica (Traducc. Arantxa Azurza, Madrid, Civitas Ediciones).

Young, Ernest A. (2000): "Constitutional Avoidance, Resistance Norm, and the Preservation of Judicial Review", en: Texas Law Review (vol. LXXVIII).

Zaffaroni, Raúl et al. (2002): Derecho Penal. Parte General, 2ª edición (Buenos Aires, Ediar).

\section{JURISPRUDENCIA CITADA}

STC español 222/1992, de 11 de diciembre.

Sentencia Tribunal Constitucional, rol 1584-09, de 17 de junio de 2010, requerimiento de inaplicabilidad por inconstitucionalidad. Disponible en: http:// www.tribunalconstitucional.cl/wp/expedientes.

Sentencia Tribunal Constitucional rol 1484, de 5 de octubre de 2010, requerimiento de inaplicabilidad relativo al art. 186 CPP. Disponible en: http:// www.tribunalconstitucional.cl/wp/expedientes.

Sentencia Corte Suprema, rol 4949-2015. 